THURSDAY, SEPTEMBER 20, 1883

\section{SCIENCE WORTHIES}

XXII.-ARTHUR CAYLEY

I $T$ is natural that the public in general should wish to know something of the life and work of one whom the British Association for the Advancement of Science has honoured by placing him this year at its head, an honour indeed which could not much longer have been withheld, considering the foremost place which our new President occupies among English mathematicians. But when asked to tell the story I am tempted to exclaim with the needy knifegrinder-.

"Story, God bless you, there is none to tell, Sir."

The quiet life of a student is not likely to be rich in sensational incidents, and of the nature of the work done by a labourer in the field of pure mathematics it is not possible to give more than a vague idea to the outside world. Some slight sketch I must attempt to give, and in doing so I must express my obligations to Mr. J. W. L. Glaisher, without the help of whose greater knowledge of Cambridge matters and of the recent progress of mathematics I could not have undertaken this task.

Arthur Cayley was born August 16, 1821. His father, a grandson of Cornelius Cayley - who was Recorder of Kingston-on-Hull from 1725 to $177 \mathrm{I}-$-was settled at St. Petersburg as partner in the firm of Russian merchantsThornton, Melville, and Cayley. It was during a short visit of his parents to England that their second son, Arthur, was born at Richmond, Surrey. An elder brotber had died in infancy; a younger brother has since become well known as an Italian scholar and a translator of Dante. In 1829 the family returned permanently to England, and after a while fixed their residence at Blackheath. At a very early age Arthur gave the usual indication by which mathematical ability is wont first to show itself, namely, great liking and aptitude f $r$ arithmetical calculations. A lady, who was one of his first instructors, has told that he used to ask for sums in Long Division to do while the other little boys were at play. After four years' teaching at a private school at Blackheath he was sent at the age of fourteen to King's College School, London, the principal of which (Hugh Rose), being struck by the indications of mathematical genius which he gave, prevailed on his father to abandon his intention of bringing the boy up to his own business and induced him to send him instead to Cambridge, where he entered Trinity College at the rather unusually early age of seventeen. At his college examinations Cayley was first by an enormous interval; but it was fortunate for him that the wares in which he dealt were those which fetched the highest price; for, if classics had been given the preference over mathematics instead of vice versá, he had in his class at Trinity College two most formidable competitors, namely, Mr. Munro, the well known scholar and editor of Lucretius, and Mr. Justice Denman, who afterwards came out as Senior Classic at the same time that Cayley came out as Senior Wrangler and first Smith's Prizeman.

This was in 1842 . In University as in other harvests, VOL. XXVIIL.-No. 725 there sometimes comes a run of unusually good years, and this certainly appears to have been the case at the period in question. The Senior Wrangler in 1840 was Leslie Ellis, in 1841 Stokes, in 1842 Cayley, in 1843 Adams; the last three of whom have, for now over twenty years, given lustre to the Cambridge mathematical school, of which they have formed part of the working staff. I do not know whether Cayley's success at the Tripos Examination was as little a surprise to himself as it was to others. Stories were current in Cambridge at the time of the equanimity with which he received the news of his success. The best authenticated one is that he was on the top of the coach on a night journey from London to Cambridge when the tripos list was put into his hands; he quietly put it into his pocket, resigning himself very contentedly to the necessity of waiting till the morning light for a knowledge of its contents. Cayley's name cannot be added to the list of those who have combined distinction in the boats or on the cricket field with high University honours. He was, however, an active pedestrian, and was a member of the Alpine Club in its comparatively early days.

While still an undergraduate, Cayley commenced his career of mathematical publications by a paper in the Cambridge Mathematical Journal for $\mathrm{I} 84 \mathrm{I}$. This periodical had been founded a little time before by Leslie Ellis, who has been just mentioned, in conjunction with his friend, Mr. Gregory, who thereby renderef a service to English mathematics that it would be difficult to estimate. One who devotes himself to original mathematical research must make up his mind to forego the pecuniary rewards which attend other forms of successful literary labour. The public which he addresses is so limited that, instead of expecting to be paid for what he writes, he has to think how he can give it to the world without too severe pecuniary loss. If it were not for the belp given by learned societies and by mathematical periodicals, every mathematician who was not rich would be forced to keep his discoveries to himself, and on such terms few would have spirit to persevere in research. At the time of which I speak mathematical periodicals open to young students scarcely existed, so that to young mathematicians doubtful of the value of their own speculations, and whose modesty would hardly permit them to ask for publication from the Royal Society, an immense stimulus was given by the foundation of the periodical just mentioned, the Cambridge Mathematical Journal, afterwards continued under the names of the Cambridge and Dublin Mathematical Journal and the Quarterly Journal of Mathematics. This journal roused the energies of the younger members of the University by making known to them that others of no higher standing than themselves were engaged in original research and by promising them the means of publishing whatever they might discover; and certainly it is no small thing that it can boast to have given Cayley his first opportunity of coming before the world.

His prodigious activity however could not long be content with a single outlet, and there were few organs of mathematical publication at home or abroad which did not receive communications from him. If his memoirs were now collected, they would form a mass exbibiting a spectacle of enormous literary industry. It appears, $\mathrm{Y}$ 
however, not to have been until i 852 that he addressed a memoir to the Royal Society, of which he was elected a Fellow in the same year.

His mathematical activity during this period was the more surprising, as he was able to devote to these studies only a limited portion of his time. He had been elected a Fellow of Trinity College in 1842 ; but as he was not willing to take Holy Orders, this was but a temporary provision, for he could only hold his Fellowship for seven years after his Master's degree. It became necessary for him therefore to look out for some profession more remunerative than mathematics, and very soon after taking his Master's degree he became a pupil of the eminent conveyancer, Mr. Christie. It is said that when offering himself as a pupil he modestly suppressed all mention of his antecedents, and that Mr. Christie was much surprised to find out on cross-examining him that he had to do with a Senior Wrangler and Fellow of Trinity. However this may be, he soon became Mr. Christie's favourite pupil, as indeed was not wonderful in the case of one who possessed a very clear head, immense capacity for work, and the power of throwing his whole mind into the work on which he was at the time engaged. After he was called to the bar he never had occasion to look elsewhere for business, for Mr. Christie was always glad to supply him with as much conveyancing work as he was willing to undertake. I have been told that some of his drafts were made to serve as models for students. But nothing that her wealthy rival had to offer could seduce Cayley into unfaithfulness to his first love, Mathematics. For Mathematics he always jealously reserved a due portion of time free from the encroachments of his business relations with Law, and it was during the time of his legal practice that some of his most brilliant mathematical discoveries were made. At last he obtained release from the embarrassment of a divided allegiance. By placing Lady Sadler's trusts on a new footing and founding the Sadlerian Professorship, his University was able to invite him to return, and he gladly accepted what was at the time a very modest provision, but which would enable him to give his whole time to the pursuits most congenial to him. Some time after his return to Cambridge his pecuniary position was improved. His College, which on his return bad speedily made him an honorary Fellow, after a time reelected him to a foundation Fellowship, necessarily a very rare distinction, since the reelection of an ex-Fellow involves the exclusion of the claims of a younger candidate. Later still, in the course of University legislation about Professorships, the position of the Sad. lerian Professorship was improved. But these things could not have been foreseen at the time that Cayley accepted the office.

It was in 1863 that, after fourteen years of chamber life in Lincoln's Inn, he married and settled perm anently in Cambridge. He never would own to any regret when his friends spoke to him of the prospects of professional advancement which he sacrificed by not remaining at the bar. He knew what mode of life would best promote his own happiness, and he had strength of mind to follow it without troubling his head about the riches or honours a different course might bring. His mathematical work gave him pleasure which he never found in law; and in his hatred of unnecessary words he was once wicked enough to say that the object of law was to say a thing in the greatest number of words, and of mathematics to say it in the fewest. But, jesting apart, the University had no reason to regret the legal training and knowledge which he had acquired during his absence from it. It has much added to his usefulness as a member of the Council of the Senate, where his opinion has carried the greatest weight, and it has enabled him to be particularly useful both to his College and to the University in the drafting of new statutes and in the necessary preliminary deliberations. At the last contested Parliamentary election Cayley presided at one of the three polling places, and gave universal satisfaction, hearing patiently the arguments on both sides on all disputed points, and then promptly making a decision in a few words in such a way as to inspire general confidence.

But after all it is as a mathematical professor that Cayley is eminently "the right man in the right place." No one could be better fitted to discharge the duties prescribed for the Sadlerian Professor, "to explain and teach the principles of pure mathematics, and to apply himself to the advancement of the science." It is seldom that one man so well combines the two qualifications here indicated, viz. power to teach what is known already, and ability to extend the boundaries of knowledge. It constantly happens that men of great originality of genius find it irksome to study what has been done by others. And now every department of science has so enlarged its borders that it has not only bccome impossible for one man to master the whole circle of the sciences; but even a single department, such as pure mathematics, includes under it so great a variety of subjects that most men are content to be specialists, and, devoting themselves to their favourite topic, are satisfied with a very superficial knowledge of other branches. Cayley is quite as distinguished for the amount and universality of his reading as for his power of original work, and may fairly count as the most learned mathematician of the present day. I suppose that, if all European matbematicians could be subjected to a tripos competition, no matter who might come out first on the "problem" papers, Cayley would be far ahead in the "book work." And his tastes are so catholic that no form of mathematics comes amiss to him. I remember how we in Dublin were struck by his proficiency in pure geometry, a subject then much cultivated with us, but which we had been accustomed to look on as too little esteemed at Cambridge.

This wideness of knowledge has made Cayley invaluable as a mathematical referee. To several scientific societies (the Royal Society, the Mathematical Society, the Royal Astronomical Society, the Cambridge Philosopbical Society) he has long been a principal adviser as to the merits of mathematical papers presented for publication, no one being more willing to take the trouble of examining such papers, or being better able to pronounce how much of their contents is new or important. And no one could te more ready and obliging with his advice to private students who have desired to interest him in their investigations, and to be assured by him that no unscrupulous predecessor has plagiarised their discoveries. Repeatedly have foreign mathematicians expressed their surprise at the rapidity with which he has dealt with such inquiries, an answer commonly coming by return of post, probably 
giving a new proof of some of the results, or pointing out that some of them were capable of greater generalisation. By his services in this way he has made himself so widely popular that if European mathematicians had to elect themselves a head I could not name any one likely to have a larger number of votes.

With respect to Cayley as an original inquirer, his special merit has in my opinion been truly seized by $\mathrm{Mr}$. Glaisher, who has described him as the greatest living master of algebra. While, as I have said, no part of mathematics comes amiss to him, he is always happiest when he can translate his theorems into pure algebra and show that a proposed result is but the expression of an algebraical fact. In this respect he differed from H. J. Smith, by whose recent loss English mathematics has so terribly suffered, who was entirely arithmetical in his thoughts and work.

Mathematicians, like chess-players, may be diviled into the book-learned and the original, the highest amount of excellence being attained by those who combine great knowledge of books with the power to strike into new paths of their own. Of this I have spoken already. But there is another division of chess-players, the solid and the brilliant, some being full of ingenious devices which, however, will not bear a careful examination; others being quite free from mistake but wooden in their style. Cayley combines the excellences of the two kinds in a very high degree, though his merits in the one respect appear to me to be more marked than in the other. Men weak in power of calculation have often exhibited beautiful exercises of ingenuity in their attempts to arrive at results by some shorter process. Such a master of algebra in all its forms as Cayley was not to be dismayed by any amount of calculation, and he therefore has been able to trample down many a difficulty which an inferior in this respect might have evaded by some ingenious oblique method.

As Cayley is not afraid of hard work himself, so it is necessary for the readers of his papers not to be easily discouraged by formidable calculations. But in my opinion it is not this so much that makes Cayley's papers difficult to read as the fact that he usually proceeds by the synthetic, not the analytic, method. It usually happens that a mathematical inquirer begins by proposing to himself some comparatively simple question. By the time he has found the answer to it, the subject opens on him; the first question suggests others, the theorem first discovered is found to admit of wide generalisations, and perhaps it may be found that these could have been arrived at in quite another way. When the time comes for the inquirer to publish his results to the world, the most attractive course is to take his readers by exactly the same road he has travelled himself, beginning with the simple problem which first attracted attention, and leading on step by step to the highest results arrived at. Cayley on the contrary usually begins by trying to establish at once the highest generalisation he has rezched, writing down equations and proceeding to make calculations as to the good of which he has not taken his readers into his confidence. The consequence is that few master his papers but those who have found a clue to them by some previous work in the same direction.

I fancy that the difficulty of Cayley's papers is to be accounted for by his having had comparatively little experience in teaching mat hematics until rather late in life, and then only to students of the highest order. He lectured for a few years at Trinity after taking his degree, but I dare say that he did wisely in going to the bar instead of making a livelihood by mathematical teaching at Cambridge, for one who loved mathematics so much for its own sake, would hardly sympathise with the many whose only object in coming to him would be to learn how they could successfully get through an examination. On his return to Cambridge he possibly would have extended his influence more widely if he had taken what may seem the lazier course of giving the same series of lectures year after year. But Cayley preferred to give his classes his latest and highest work, and each year has taken for his subject that of the memoir on which he was for the time engaged. The result has been that he has been brought little in contact with any but the most advanced students, who alone could profit by such instruction, nor even they, indeed, unless they were as high-minded as himself, and were content to spend a great amount of time and labour on work that could not "pay" at the great University examination.

As I have spoken of Cayley's lectures I ought not to omit to mention the honour done him by the heads of the Johns Hopkins University of Baltimore, Maryland, an institution which numbers among its professors, as head of its mathematical department, Cayley's distinguished friend and fellow worker, Sylvester. They invited Cayley to go over to lecture at Baltimore in the winter session of 1882. He accepted a proposal in every way so flattering, and lectured at Baltimore in the months of January to May, I882, returning to England in June. His subject was Elliptic and Abelian functions, and his lectures, in which he considered from an algebraic point of view the geometrical theories of Clebsch and Gordan, were given for publication to the American Joumal of Mathematics, and are likely to form a classic memoir on the subject.

As I have said so much of Cayley's mathematical labours, it will probably be expected that I should speak a little less vaguely, and endeavour to explain more particularly the nature and progress of his discoveries; yet it is not easy to make the history of discovery in the higher branches of pure mathematics readable even for so select a class as the subscribers to NATURE. It requires but a small stock of technical knowledge to enable a reader to follow with interest a history of mechanical inventions, or of discoveries admitting of useful practical applications, or of the skilled organisation of labour; but what is to be said of the work done by a solitary student in his closet, the result of which will not so much as cheapen one yard of calico?

It would be out of place if I were to take trouble here to show that pure mathematics have after all added much to the material wealth of the world. My subject is the life of a great artist who has had courage to despise the allurements of avarice or ambition, and has found more happiness from a life devoted to the contemplation of beauty and truth than if he had striven to make himself richer, or otherwise push himself on in the world. We do not classify painters according to the numbers capable of appreciating their respective productions. On the contrary, we can understand that it is often the lowes 
style of art which will attract round it the largest circle of admirers. So the fact that it is a very limited circle which is capable of appreciating the beauty of the work done by a great mathematician should not prevent men from understanding that it is like the work done by a poet or a painter, work done entirely for its own sake, and capable of affording lively pleasure both to the worker himself and his admirers, without any thought of material benefit to be derived from it.

But in point of fact mathematics stand midway between the arts which minister to man's sense of beauty and those which supply his material comforts. The name "pure mathematics" suggests that there is such a thing as "applied mathematics," and it is well known that the mathematician furnishes the instruments employed by cultivators of sciences whose practical utility is beyond dispute. If the mathematician did no more than manufacture such instruments precisely as the demand arose for them, his might count as one of the arts which are valued only for their practical utility. But actually the invention of the mathematical instruments usually comes first, and the use to be made of them is found out afterwards. The stock example of the kind is the debt which physical astronomy owes to the labours of the early geometers on the theory of conic sections, a theory cultivated without any suspicion that it could be turned to practical account. Yet it was because Newton was in his day the greatest master of this as of every other branch of pure mathematics that he was able to bring all the motions of the heavenly bodies under the dominion of mathematical calculation, and to convert the moon into a timepiece by which the mariner can ascertain his position on the seas. With the advance of physical science greater refinement and power in the mathematical instruments of investigation have become necessary; but pure mathematicians have ever outrun the demands of the practical workers, for instrument-making has delights of its own. The late Lord Rosse I have no doubt found more pleasure in devising the innumerable ingenious and beautiful contrivances necessary for the manufacture of his huge telescope than he ever did from observing with it after it was made. It is impossible for any one now to say what advantages future investigators will derive from the perfection to which the mathematical instruments have been brought by the labours of such men as Cayley, who have invented mathematical steam hammers by which ponderous masses of formulæ can be manipulated with ease and calculations made simple which in former times were looked on as impracticable.

There is hardly anything that comes under the head of pure mathematics at which Cayley has not worked, but it will be enough if I try to say something as to that by which his name is likely to be best remembered-his creation of an entirely new branch of mathematics by his discovery of the theory of invariants, which has given quite a new aspect to several departments of mathematics. It has introduced such a host of new ideas, and consequently of new words, that a Senior Wrangler of forty years ago, who had not kept pace with modern investigations, would find, on taking up a book of the present day on geometry or algebra, that he could not read it without a glossary, and must go to school again to learn what the writer was speaking of. It would be out of place if I were to enter into a very long technical exposition here, but it is possible, without assuming in the reader more than a moderate knowledge of analytic geometry, to make him at least understand what the word "invariant" means. Suppose that we have written down the general equation of a curve of any degree, and also have found the relation that must subsist between the coefficients in order that the curve should assume some special form. For simplicity I suppose the equation to be of the second degree, and I take the well known relation between the coefficients which is satisfied when the curve represented reduces itself to two right lines. Now imagine the equation to be transformed to any new coordinates whatever, this can make no change in the form of the curve represented. If the relation in question were satisfied by the coefficients of the original equation, it must also be satisfied by the coefficients of the transformed equation. But by actually performing the transformation we can express these new coefficients in terms of the old ones and of the constants introduced in the process of transformation. The expression will be complicated enough, and that of the relation of which $I$ am speaking still more so. But since the relation must vanish whenever the corresponding relation expressed in terms of the old coefficients vanishes, the one must contain the other as a factor. The remaining factor, it will be seen on examination, contains nothing but the constants introduced by transformation. All this can be verified by actual work; but the result which I have stated can be foreseen without any calculation.

The principle which I have described has proved to be very fertile in applications. The late Dr. Boole made, in 184r, some interesting use of a simple case of the same principle. But it was Cayley who set himself the problem to determine a priori what functions of the coefficients of a given equation possess this property of invariance, viz., that when the equation is linearly transformed the same function of the new coefficients is equal to the given function multiplied by a quantity independent of the coefficients. The result of his investigations was to bring to light a number of important functions (some of them involving the variables as well as the coefficients) whose relations to the given equation are unaffected by linear transformation. And the effect has been that the knowledge which mathematicians now possess of the structure of algebraic forms is as different from what it was before Cayley's time as the knowledge of the human body possessed by one who has dissected it and knows its internal structure is different from that of one who bas only seen it from the outside.

In an age when the work of mathematical research is so actively carried on, whenever one worker finds a nugget there is an immediate rush to the spot of other searchers. In the present case Cayley's friend Sylvester was one of the first on the spot, and both being resident in London were able by frequent oral communication to stimulate each other's ideas. As I am not relating the history of mathematical science, I need not name the foreign mathematicians who rapidly came in to labour in the same field; but it is agreed on all hands that it was Cayley who both discovered the "diggins" and got out some of the biggest nuggets. It is not always the case that the history of a mathematical discovery has not to 
tell of some contests for priority. All pure mathematics consists in the drawing out of ideas latent in admitted principles, and it is a curious fact how men will fail to draw the consequences which to another will appear irresistibly suggested by something they have themselves asserted, and consequently how near they will come to the brink of a discovery without actually making it. And con'roversies as to mathematical priority naturally arise because it seems so cruel to the man who has taken all the steps except the very last, that another should step in and get the credit of the discovery, when it seems to him that he himself had done all the difficult part of the work and the other only drawn an inference so simple that no credit should be given to any one for making it. If no controversy of the kind has arisen in the present case, perbaps the cause is not exclusively the indisputable character of Cayley's claims, but something is also due to the moral nature of the man. His motto has always been "esse quam videri," and I do not know any one to whom it would be more repulsive to engage in a personal contest by claiming for himself a particle of honour or of money more than was spontaneously conceded. He would be apt to take for his model the patriarch Isaac, who, when the Philistines claimed a well which he had dug, went on and dug another, and when they claimed that too, went on and dug a third.

The place of a more minute account of his mathematical discoveries may be supplied by a mention of the wide recognition which his labours have received. He was given the honorary degrees of D.C.L. Oxford, 1864 , LL.D. Dublin, I865, and was elected Fellow or Correspondent of the following Societies:-Philosophical Society, Manchester, I859; French Institute, I863; Royal Societies, Edinburgh and Berlin, I865; Boston, I866; appointed a Member of the Board of Visitors, Greenwich Observatory, I866; Milan, I868; St. Petersburg and Göttingen, I871 ; Royal Irish Academy, I873; Upsala, Leyden, and Rome, 1875; Hungary, x881 ; Sweden, 1882. I should add that the Royal Society awarded him a Royal Medal in 1859 , and last year (1882) the Copley Medal; the latter a distinction seldom conferred on a pure mathematician.

Though his principal interests are mathematical, they are far from being exclusively so. $\mathrm{He}$ is a good linguist, and, as was said of Moltke, there are few European languages in which he does not know how to hold his tongue. $\mathrm{He}$ is chairman of the Association for Promoting the Higher Education of Women. When seats in the University Council are contested, his name always appears on both the rival lists. By all who know him he is as much respected as a high-minded man as he is admired as a mathematician.

GEORGE SALMON

\section{BENTHAM AND HOOKER'S " GENERA PLANTARUM"}

Genera Plantarum ad exemplaria imprimis in herbariis Kewensibus servata definita. By G. Bentham and J. D. Hooker. 3 vols. (London, 1862-1883.)

THE completion of the "Genera Plantarum" of Messrs. Bentham and Hooker, an event long impatiently desired by all botanists, has been recently effected by the publication of the second and concluding part of the third volume. This great work has required more than fiveand-twenty years of assiduous labour, during which the authors have devoted themselves to their formidable task with untiring perseverance, and with a degree of unity both in the plan and the execution of the work which would have been impossible but for their constant daily intercourse, and their relations of intimate personal friendship.

Before undertaking the publication of the "Genera "its authors had already given to the world important works which had placed them in the foremost rank as botanists, and both were familiarly acquainted with the scientific wealth accumulated in the museums and gardens at Kew. Mr. Bentham, whose botanical collections were united to those of the Royal Herbarium as long as thirty-six years ago, had already in connection with his various works and memoirs had occasion to study nearly the entire vegetable kingdom; while Sir Joseph Hooker, in addition to an equally wide range of study, had the inestimable advantage of having during his extensive travels been able to observe in the living state numerous species of many genera characteristic of the tropical and antarctic regions, and of having fixed their analytical characters by sketches and diagrams of singular elegance and accuracy.

With a rare amount of abnegation of personal feeling the authors of this work were content to let it go forth under their joint names, without in any way indicating the separate share contributed by each of them, desiring, as it would appear, that it should be regarded as the collective result of their joint labours-the product of two minds working harmoniously for a common object. Only very recently, under the pressure of urgent requests from many different quarters, Mr. Bentham consented, in a short note communicated to the Linnean Society, ${ }^{1}$ to explain in a summary way the share contributed by each of the authors. This is of so much interest to botanists that the present writer does not hesitate to give here the substance of Mr. Bentham's note.

The Polypetale, which fill the first volume, were pretty equally divided. While Mr. Bentham was engaged on the earlier orders, Sir J. Hooker undertook the Cruciferce, Capparidea, and Resedacea; and to his share also fell most of the numerous families of the Disciflora, while Mr. Bentham elaborated the remaining families of the Thalamiflora, along with the Linea, Humiriacea, Geraniacece, and Olacinece. Of the group of the Calyciflore it was natural that Mr. Bentham should undertake the Leguminose, which he had already illustrated by a series of important memoirs, and to him also fell the Myrtacea, Umbelliferce, and Araliacea. The remaining families of this group, including the Rosacee, Saxifragea, Melastomacea, and Cucurbitacea, besides many others less important, were assigned to Sir J. Hooker.

The first portion of the second volume is almost entirely occupied by the two great families of Rubiacece and Compositce. To the former of these Sir J. Hooker devoted two years of constant study which involved very numerous dissections of a difficult nature, and he also elaborated the Caprifoliacea. During the same period Mr. Bentham was mainly occupied with the vast family of Compositce, comprising nearly 800 genera, and not much I "On the joint and separate work of the authors of Bentham and Hooker's "Genera Plantarum." "Fournal of the Linnean Socicty-Botany, vol. xx. pp. 304-308. 